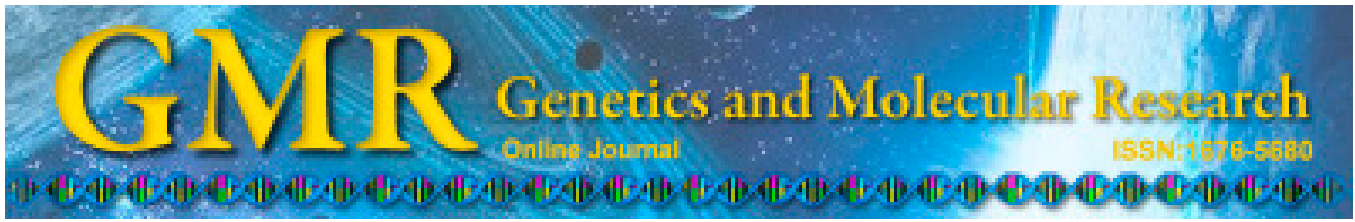

\title{
FSHR gene Thr307Ala and Asn680Ser polymorphisms in infertile men: an association study in North China and meta-analysis
}

X.Q. Wu, S.M. Xu, Y.Q. Wang, Q. Li, Z.Q. Wang, C.L. Zhang and Y. Shen

Center for Reproductive Medicine, Shanxi Maternal and Child Health Care Hospital, Taiyuan, China

Corresponding author: X.Q. Wu

E-mail: xueqingwu416@126.com

Genet. Mol. Res. 14 (2): 5592-5601 (2015)

Received July 30, 2014

Accepted January 19, 2015

Published May 25, 2015

DOI http://dx.doi.org/10.4238/2015.May.25.11

\begin{abstract}
Male infertility is a complex multifactorial and polygenic disease, and genetic factors play an important role in its formation and development. Recently, the association between follicle stimulating hormone receptor $(F S H R)$ gene polymorphisms and male infertility risk has attracted widespread attention due to the unique biological functions of FSH. The aim of this study was to further explore the associations between the Thr307Ala and Asn680Ser polymorphisms of the FSHR gene and male infertility. A case-control study of 212 infertile and 164 fertile men from North China was performed. FSHR polymorphism genotypes were obtained through direct DNA sequencing. A metaanalysis was also performed. In the single-site association analysis, no significant associations were identified between FSHR Thr307Ala and Asn680Ser polymorphisms and male infertility $(\mathrm{P}>0.05)$. However, we found that the combined genotypic frequency of Thr/Ala + Asn/ Asn was higher in infertile patients than in controls (6.6 vs 1.8\%; odds ratio $(\mathrm{OR})=3.795 ; 95 \%$ confidence interval $(\mathrm{CI}): 1.072-13.434, \mathrm{P}$ $=0.027)$. In the meta-analysis, there was also no evidence of FSHR polymorphism (rs 6165 and rs 6168) association with male infertility
\end{abstract}


$(\mathrm{P}>0.05)$. However, we found that the combined genotypes Thr/Thr + Asn/Asn had an increased risk of male infertility $(\mathrm{OR}=1.238 ; 95 \% \mathrm{CI}$ : 1.001-1.537, $\mathrm{P}=0.049$ ). Our studies further confirmed reports that there were no significant associations between the FSHR Thr307Ala and Asn680Ser polymorphisms and male infertility risk. However, a combined FSHR genotype showed significant association with male infertility.

Key words: Male infertility; Idiopathic infertility; Meta-analysis; Follicle-stimulating hormone receptor;

Single nucleotide polymorphisms

\section{INTRODUCTION}

Male infertility is a complex disease that involves both environmental and genetic factors. It has been identified that approximately $15 \%$ of infertility cases could be attributed to genetic defects, including congenital hypogonadotrophic hypogonadism, congenital absence of the vas deferens, and primitive testicular failure (Krausz, 2011). However, there are still many male patients with infertility for whom the exact etiology is unknown; this is described as idiopathic male infertility. Because idiopathic infertility accounts for approximately $50 \%$ of male infertility (Forti and Krausz, 1998), a clear understanding of the pathogenesis of male infertility is critical for management of this disorder. Nowadays, an increasing number of researchers have focused their attention to the study of the correlation between genetic polymorphism with male infertility; e.g., within the cytochrome P4501A1 (CYP1A1) (Luo et al., 2014), sex hormone-binding globulin (SHBG) (Lazaros et al., 2008), and follicle stimulating hormone receptor (FSHR) (Ahda et al., 2005) genes, among others.

FSH plays an important role in the maintenance of qualitatively and quantitatively normal spermatogenesis (Nieschlag et al., 1999; Plant and Marshall, 2001). Its biological effects are exerted through binding with its receptor (FSHR), a member of the G proteincoupled receptor family. The FSHR gene consists of 9 introns and 10 exons and a promoter region and is located on chromosome 2p21 (Simoni et al., 1997). Mutation screening has identified several single nucleotide polymorphisms (SNPs) in the FSHR gene (Themmen and Huhtaniemi, 2000). Among these, the linked SNPs at positions 307 and 680 in exon 10 of the FSHR gene (GenBank accession No. NM_000145) have attracted widespread attention. However, despite the many studies that have investigated the possible associations between the Thr307Ala and Asn680Ser polymorphisms in the FSHR gene and male infertility, the findings remain unclear. Shimoda et al. (2009) reported that the combination of heterozygous FSHR variants might be responsible for male infertility in a Japanese population. Similar results were found by Safarinejad et al. (2011) in an Iranian population, and Song et al. (2013) in a Chinese population. Therefore, FSHR polymorphisms are thought to play a certain role in male infertility.

To further explore the association between Thr307Ala and Asn680Ser polymorphisms in the FSHR gene and male infertility, a case-control study of 212 infertile and 164 fertile men from North China was carried out, as well as a meta-analysis performed by combining our results with previous reports. 


\section{MATERIAL AND METHODS}

\section{Study subjects}

Both male patients with infertility $(\mathrm{N}=212)$ and controls $(\mathrm{N}=164)$ were recruited by the Reproductive Medicine Center, Shanxi Maternal and Child Health Care Hospital, Taiyuan, China from October 2012 to December 2013. All subjects were of Han ethnicity from the Shanxi Province in North China. No difference in age was found between patients (32.753 \pm 5.52 years) and controls ( $30.805 \pm 2.87$ years) $(\mathrm{P}>0.05)$. According to the World Health Organization guidelines (WHO Laboratory Manual for the Examination and Processing of Human Semen, 5th edn., 2010), routine analysis of semen was conducted at least twice. The study was approved by the local Medical Ethical Committee and all participants provided consent.

The patients selected consisted of infertile men with idiopathic infertility ranging from oligospermia to azoospermia. Other diseases that could cause secondary infertility, such as obstructive azoospermia, karyotype abnormalities, Y chromosome microdeletions, and cryptorchidism, were excluded.

The controls consisted of normospermic patients who were from couples suffering infertility due to the woman's issues and no genetic or reproductive tract disease.

\section{Genomic DNA extraction and genotyping}

Genomic DNA was extracted from heparinized venous blood with the E.Z.N.A. Blood DNA Kit (Omega, Bio-Tek, Norcross, GA, USA) according to the manufacturer protocol. Each $50-\mu \mathrm{L}$ polymerase chain reaction (PCR) contained $100 \mathrm{ng}$ genomic DNA, $0.3 \mathrm{M}$ forward and reverse primer, $0.2 \mathrm{mM}$ dNTPs, $2.5 \mathrm{U}$ Taq DNA polymerase, and $2 \mathrm{mM} \mathrm{MgSO}_{4}$. To genotype codon 680, we used forward primer: 5' - TTT GTG GTC ATC TGT GGC TGC - 3' and reverse primer: 5' - CAAAGG CAA GGA CTG AAT TAT CAT T - 3', whereas for codon 307, we used forward primer: 5' - CCT GCA CAA AGA CAG TGA TG - 3' and reverse primer: 5' - TGG CAA AGA CAG TGA AAA G - 3'. The PCR amplification was performed by an initial step at $94^{\circ} \mathrm{C}$ for $5 \mathrm{~min}$; followed by 30 cycles consisting of denaturation at $94^{\circ} \mathrm{C}$ for 30 $\mathrm{s}$, annealing at $55^{\circ} \mathrm{C}$ (for Ala307Thr) or $60^{\circ} \mathrm{C}$ (for Ser680Asn) for $30 \mathrm{~s}$, and elongation at $72^{\circ} \mathrm{C}$ for $1 \mathrm{~min}$; with a final extension at $72^{\circ} \mathrm{C}$ for $10 \mathrm{~min}$. All PCR products were subjected to direct DNA sequencing (Figure 1).

\section{Meta-analysis}

We searched the potential eligible articles published in English and Chinese using PubMed, Google Scholar literature databases, the Chinese VIP database, the Chinese National Knowledge Infrastructure (CNKI) database, and the Chinese Wanfang database. The literature search was updated on February 20, 2014, using the key words "follicle stimulating hormone receptor or FSHR" and "Thr307Ala or rs6165" and "Asn680Ser or rs6168" and "variant or genotype or polymorphism or single nucleotide polymorphism or SNP" and "male infertility or idiopathic infertility". A total of nine articles involving an association study with the FSHR gene Thr307Ala polymorphism were identified, and a total of 12 publications with Asn680Ser; four of these involved the combined genotypes of FSHR polymorphisms and the associated risk of male infertility. 
A
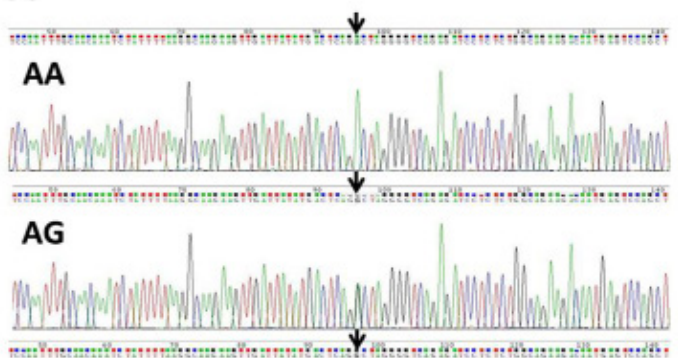

GG

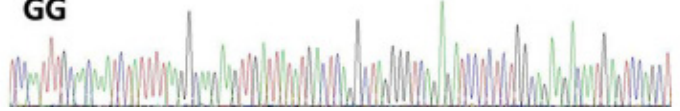

B

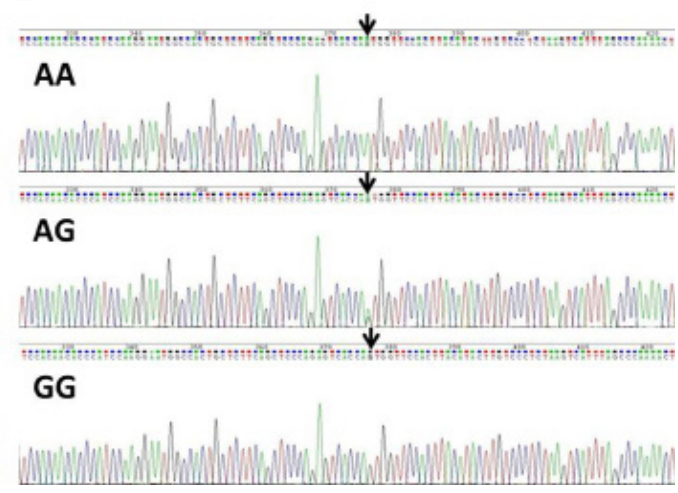

Figure 1. DNA sequencing results for the FSHR gene Thr307Ala and Asn680Ser polymorphisms. A. DNA sequencing of the Thr307Ala polymorphism (AA, AG, GG) is indicated by the arrow. B. DNA sequencing of the Asn680Ser polymorphism (AA, AG, GG) is indicated by the arrow. FSHR: follicle stimulating hormone receptor.

\section{Statistical analysis}

\section{Case-control study}

Genotype and allele frequencies were compared between patients and controls using a $\chi^{2}$ test. The odds ratio (OR) and their respective $95 \%$ confidence intervals $(95 \% \mathrm{CIs})$ were calculated. Hardy-Weinberg equilibrium (HWE) of each SNP in the patient and control groups was examined to check the genotypic distribution using a $\chi^{2}$ test. Statistical analyses were performed using the SPSS 16.0 statistical package (SPSS, Chicago, IL, USA). All reported P values are two-tailed and were considered to be statistically significant if $\mathrm{P}$ was $<0.05$.

\section{Meta-analysis}

For each case-control study, we also first tested whether the genotype frequencies were in HWE using a $\chi^{2}$ test. ORs and $95 \%$ CIs were calculated as the strength of association between Thr307Ala and Asn680Ser polymorphisms and male infertility. The pooled ORs and their corresponding 95\% CIs were computed for the allele ( $\mathrm{G} v s \mathrm{~A}$ ), homozygous (GG vs $\mathrm{AA}$ ), heterozygous (AG vs AA), and dominant (AG/GG vs AA) and recessive (GG vs AA/ AG) models. The significances of the pooled ORs were determined by the $\mathrm{Z}$ test; $\mathrm{P}<0.05$ was considered to be statistically significant. The statistical heterogeneity among studies was assessed by Q-test and $\mathrm{I}^{2}$ statistics (Higgins and Thompson, 2002). When $\mathrm{P}>0.1$ or $\mathrm{I}^{2}<$ $50 \%$, no heterogeneity among studies was indicated, and the fixed-effects model was used; otherwise, the random-effects model was used. Subgroup analysis was performed by ethnicity. Publication bias was explored using Begg's funnel plots and Egger's regression test $(\mathrm{P}<$ 0.05 indicated statistical significance) (Egger et al., 1997; Munafo et al., 2004). Sensitivity analysis was performed after excluding each study in turn to assess the stability of the results. All statistical tests were two-sided, and $\mathrm{P}<0.05$ was considered to be statistically significant. All data analyses were performed using STATA version 12.0 (STATA Corporation LP, College Station, TX, USA). 


\section{RESULTS}

\section{Case-control study of FSHR gene polymorphisms in infertile men}

In this study, patients $(\mathrm{N}=212)$ and control individuals $(\mathrm{N}=164)$ were recruited from the Shanxi Province of North China. The results of statistical analysis of the distribution of FSHR polymorphism genotype and allele frequencies between infertile men and controls are shown in Table 1. The genotypes of FSHR codons 680 and 307 in patients and controls were in HWE, and showed a demographic representation. However, there were no significant separate associations between the Thr307 and Asn680Ser polymorphisms and male infertility risk (all $P$ values $>0.05$ ). We further checked whether the haplotypes of the two SNPs were associated with male infertility (Table 2). The results showed that the combined genotypes of $\mathrm{Thr} / \mathrm{Ala}$ + Asn/Asn had a higher frequency in infertile patients than in controls $(6.6 \% v s 1.8 \%$; OR $=$ 3.795; 95\%CI: 1.072-13.434, $\mathrm{P}=0.027$ ).

Table 1. Genotype and allele frequencies of the FSHR polymorphisms between infertile men and controls.

\begin{tabular}{|c|c|c|c|c|c|c|c|c|c|}
\hline \multirow[b]{2}{*}{ Thr307Ala } & \multicolumn{2}{|c|}{ Allele [N (\%)] } & \multirow[t]{2}{*}{$P$ value } & \multirow[t]{2}{*}{ OR $(95 \% \mathrm{CI})$} & \multicolumn{3}{|c|}{ Genotype [N (\%)] } & \multirow[t]{2}{*}{$P$ value } & \multirow[t]{2}{*}{ HW test } \\
\hline & $\operatorname{Thr}(\mathrm{A})$ & Ala (G) & & & Thr/Thr (AA) & Thr/Ala (AG) & Ala/Ala (GG) & & \\
\hline Patients & $285(67.2 \%)$ & $139(32.8 \%)$ & 0.192 & $1.232(0.900-1.687)$ & $95(44.8 \%)$ & $95(44.8 \%)$ & $22(10.4 \%)$ & 0.222 & 0.807 \\
\hline Controls & $235(71.6 \%)$ & $93(28.4 \%)$ & & & $80(48.8 \%)$ & $75(45.7 \%)$ & $9(5.5 \%)$ & & 0.108 \\
\hline Asn680Ser & Asn (A) & Ser (G) & & & Asn/Asn (AA) & Asn/Ser (AG) & Ser/Ser (GG) & & \\
\hline Patients & $292(68.9 \%)$ & $132(31.1 \%)$ & 0.359 & $1.160(0.845-1.592)$ & $100(47.2 \%)$ & $92(43.4 \%)$ & $20(9.4 \%)$ & 0.485 & 0.861 \\
\hline Controls & $236(72.0 \%)$ & $92(28.0 \%)$ & & & $82(50.0 \%)$ & $72(43.9 \%)$ & $10(6.1 \%)$ & & 0.261 \\
\hline
\end{tabular}

$\mathrm{FSHR}=$ follicle stimulating hormone receptor; $\mathrm{OR}=$ odds ratio; $\mathrm{CI}=$ confidence interval; HW test $=$ HardyWeinberg equilibrium test; P value from chi-squared test.

Table 2. Combined genotype frequencies of the FSHR polymorphisms among the patients and controls.

\begin{tabular}{lcccc}
\hline Variants & Patients $(\mathrm{N}=212)$ & Controls $(\mathrm{N}=164)$ & OR $(95 \% \mathrm{CI})$ & P value \\
\hline Thr/Thr + Ser/Ser & $3(1.4 \%)$ & $1(0.6 \%)$ & $2.340(0.241-22.702)$ & $0.635^{\mathrm{a}}$ \\
Thr/Thr + Asn/Asn & $84(39.6 \%)$ & $78(47.6 \%)$ & $0.724(0.479-1.092)$ & $0.123^{\mathrm{b}}$ \\
Thr/Thr + Asn/Ser & $8(3.8 \%)$ & $1(0.6 \%)$ & $6.392(0.791-51.630)$ & $0.084^{\mathrm{a}}$ \\
Ala/Ala + Ser/Ser & $16(7.5 \%)$ & $6(3.7 \%)$ & $2.150(0.822-5.622)$ & $0.111^{\mathrm{b}}$ \\
Ala/Ala + Asn/Asn & $2(0.9 \%)$ & $1(0.6 \%)$ & $1.552(0.140-17.270)$ & $1.000^{\mathrm{a}}$ \\
Ala/Ala + Asn/Ser & $4(1.9 \%)$ & $2(1.2 \%)$ & $1.558(0.282-8.610)$ & $0.700^{\mathrm{a}}$ \\
Thr/Ala + Ser/Ser & $1(0.5 \%)$ & $3(1.8 \%)$ & $0.254(0.026-2.468)$ & $0.322^{\mathrm{a}}$ \\
Thr/Ala + Asn/Asn & $14(6.6 \%)$ & $3(1.8 \%)$ & $3.795(1.072-13.434)$ & $\mathbf{0 . 0 2 7}^{\mathrm{b}}$ \\
Thr/Ala + Asn/Ser & $80(37.7 \%)$ & $69(42.1 \%)$ & $0.834(0.550-1.265)$ & $0.394^{\mathrm{b}}$ \\
\hline
\end{tabular}

FSHR $=$ follicle stimulating hormone receptor; OR = odds ratio; CI = confidence interval; 'Fisher's Exact Test; bPearson Chi-Square test; P value and OR $(95 \% \mathrm{CI})$ from the chi-squared test.

\section{Meta-analysis of FSHR gene polymorphisms in infertile men}

These studies represented in the meta-analysis had conducted single-site analyses FSHR polymorphism genotypes including 1897 patients and 2113 controls (for codon 307), 
and 3021 patients and 3553 controls (for codon 680). The allele and genotype distributions of infertile men and controls are presented in Table 3. Overall, there was no significant association between Thr307Ala and Asn680Ser polymorphisms and male infertility risk (for G vs $\mathrm{A}, \mathrm{GG} v s \mathrm{AA}, \mathrm{AG} v s \mathrm{AA}, \mathrm{AG} / \mathrm{GG} v s \mathrm{AA}$, or GG $v s \mathrm{AA} / \mathrm{AG}$ ) (Table 4). In subgroup analysis by ethnicity (Non-Asian and Asian), we also found no positive evidence for the association between Thr307Ala and Asn680Ser polymorphisms individually and male infertility for all genetic models analyzed. In sensitivity analyses, statistically similar data were obtained after sequentially excluding each study, which indicated that our results were statistically reliable. The Begg's funnel plots were shown to be symmetrical (for AG/GG vs AA) (Figure 2) and the Egger's regression test did not show any evidence of publication bias (for codon 307: $\mathrm{P}=$ 0.402; for codon $680: \mathrm{P}=0.465$ ). These data indicated that there was no significant publication bias in this meta-analysis.

\begin{tabular}{|c|c|c|c|c|c|c|c|c|c|c|c|c|c|c|}
\hline \multirow[b]{2}{*}{ Thr307Ala } & \multirow[t]{2}{*}{ Year } & \multirow[t]{2}{*}{ Country } & \multirow[t]{2}{*}{ Ethnicity } & \multirow[t]{2}{*}{ Patients (N) } & \multirow[t]{2}{*}{ Controls (N) } & \multicolumn{5}{|c|}{ Patients (N) } & \multicolumn{3}{|c|}{ Controls (N) } & \multirow[t]{2}{*}{ HW test } \\
\hline & & & & & & AA & $\mathrm{AG}$ & GG & $\mathrm{A}$ & $\mathrm{G}$ & $\mathrm{AA}$ & AG GG & $\mathrm{A}$ & \\
\hline Ahda Y & 2005 & Germany & Non-Asian & 341 & 186 & 101 & 166 & 74 & 368 & 314 & 74 & 35 & 225147 & 0.068 \\
\hline Pengo M & 2006 & Italy & Non-Asian & 215 & 351 & 75 & 96 & 44 & 246 & 184 & 114 & 153 & 381321 & 0.023 \\
\hline Shimoda & 2009 & Japan & Asian & 343 & 146 & 118 & 179 & 46 & 415 & 271 & 68 & 17 & 19795 & 0.560 \\
\hline Lend Ak & 2010 & Estonia & Non-Asian & 150 & 208 & 50 & 72 & 28 & 172 & 128 & 67 & 106 & 240176 & 0.526 \\
\hline Safarinejad MR & 2011 & Iran & Non-Asian & 172 & 172 & 62 & 90 & 20 & 214 & 130 & 78 & 20 & 230114 & 0.702 \\
\hline $\operatorname{LiY}$ & 2011 & China & Asian & 176 & 469 & 75 & 88 & 13 & 238 & 114 & 189 & 230 & 608330 & 0.103 \\
\hline Ghirelli-Filho M & 2012 & Brazil & Non-Asian & 138 & 217 & 33 & 72 & 33 & 138 & 138 & 74 & 54 & 237197 & 0.011 \\
\hline Song D & 2013 & China & Asian & 150 & 200 & 65 & 63 & 22 & 193 & 107 & 81 & 31 & 250150 & 0.386 \\
\hline This study & & & Asian & 212 & 164 & 95 & 95 & 22 & 285 & 139 & 80 & 75 & $235 \quad 93$ & 0.108 \\
\hline Asn680Ser & & & & & & AA & AG & GG & $\mathrm{A}$ & $\mathrm{G}$ & $\mathrm{AA}$ & AG GG & A $\quad$ G & \\
\hline Ahda Y & 2005 & Germany & Non-Asian & 438 & 304 & 126 & 216 & 96 & 468 & 408 & 101 & 143 & 345263 & 0.466 \\
\hline Pengo M & 2006 & Italy & Non-Asian & 215 & 351 & 75 & 96 & 44 & 246 & 184 & 114 & 153 & 381321 & 0.023 \\
\hline Zalata AA & 2008 & Egypt & Non-Asian & 52 & 30 & 18 & 20 & 14 & 56 & 48 & 14 & 10 & $38 \quad 22$ & 0.122 \\
\hline Shimoda C & 2009 & Japan & Asian & 340 & 146 & 131 & 164 & 45 & 426 & 254 & 72 & 12 & $206 \quad 86$ & 0.791 \\
\hline Lend Ak & 2010 & Estonia & Non-Asian & 150 & 208 & 50 & 73 & 27 & 173 & 127 & 66 & 107 & 239177 & 0.451 \\
\hline Balkan M & 2010 & Turkey & Non-Asian & 270 & 240 & 176 & 59 & 35 & 411 & 129 & 154 & 49 & 357123 & 0.000 \\
\hline Li Y & 2011 & China & Asian & 176 & 469 & 80 & 82 & 14 & 242 & 110 & 203 & 220 & 626312 & 0.221 \\
\hline Safarinejad MR & 2011 & Iran & Non-Asian & 172 & 172 & 69 & 80 & 23 & 218 & 126 & 85 & 15 & 242102 & 0.964 \\
\hline Ghirelli-Filho M & 2012 & Brazil & Non-Asian & 138 & 217 & 32 & 66 & 40 & 130 & 146 & 49 & 80 & 186248 & 0.011 \\
\hline Song D & 2013 & China & Asian & 150 & 200 & 69 & 58 & 23 & 196 & 104 & 86 & $87 \quad 27$ & 259141 & 0.506 \\
\hline Grigorova M & 2013 & Baltic & Non-Asian & 708 & 1052 & 264 & 356 & 125 & 884 & 606 & 379 & 5071681 & 1265843 & 0.943 \\
\hline This study & & & Asian & 212 & 164 & 100 & 92 & 20 & 292 & 132 & 82 & $\begin{array}{ll}72 & 10\end{array}$ & $236 \quad 92$ & 0.261 \\
\hline
\end{tabular}

HW test $=$ Hardy-Weinberg equilibrium test.

Among the studies included in the meta-analysis, four had also performed analysis of combined genotype frequencies of the FSHR polymorphisms among cases and controls (Table 5). Meta-analysis results of these studies suggested that the combined genotypes of $\mathrm{Thr} / \mathrm{Thr}+\mathrm{Asn} /$ Asn might increase the risk of male infertility $(\mathrm{OR}=1.238,95 \% \mathrm{CI}: 1.001$ $1.537, \mathrm{P}=0.049$ ). 
X.Q. Wu et al.

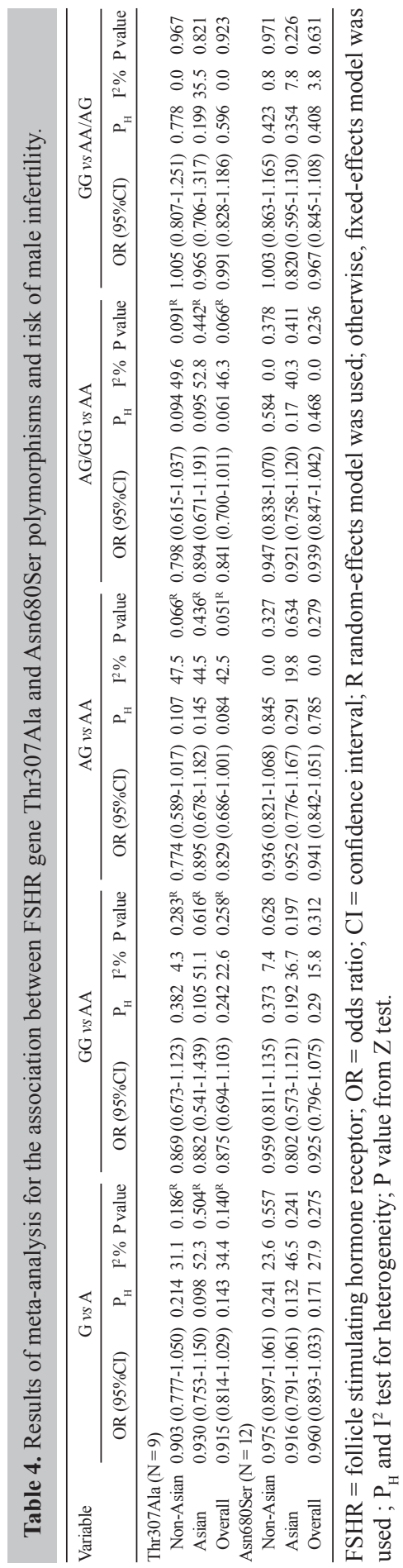


A

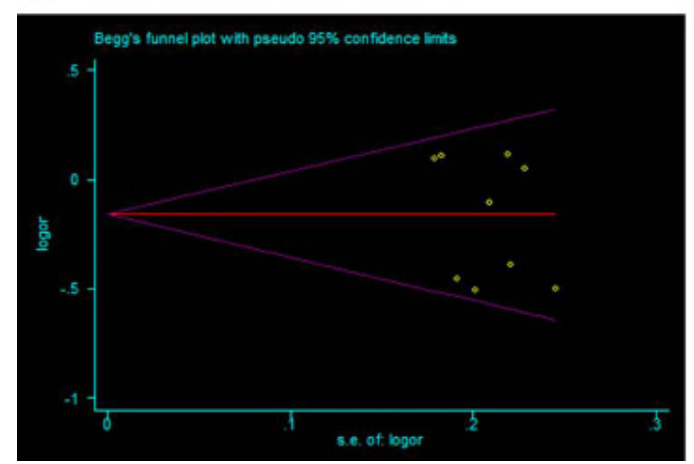

B

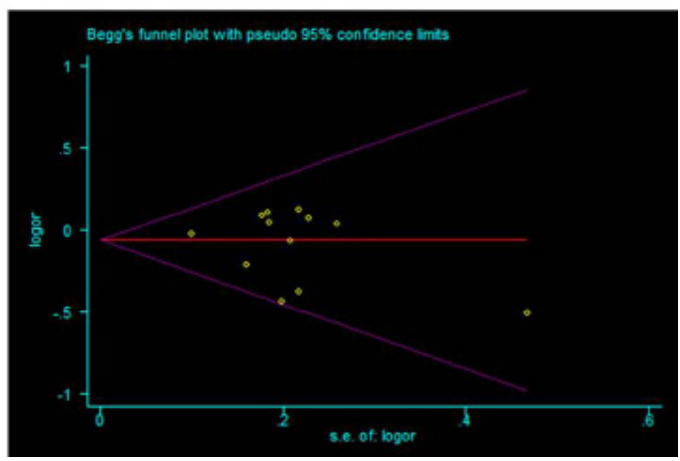

Figure 2. Begg's funnel plots for publication bias (AG/GG vs AA). Funnel plot for codon 307 (A) and for codon 680 (B).

Table 5. Results of meta-analysis for the combined genotypes of the FSHR polymorphisms among patients and controls.

\begin{tabular}{|c|c|c|c|c|}
\hline Variants & OR $(95 \% \mathrm{CI})$ & $\mathrm{P}_{\mathrm{H}}$ & $\mathrm{I}^{2}$ & $P$ value \\
\hline $\mathrm{Thr} / \mathrm{Thr}+\mathrm{Ser} / \mathrm{Ser}$ & $0.386(0.118-1.259)$ & 0.442 & $0.0 \%$ & 0.115 \\
\hline $\mathrm{Thr} / \mathrm{Thr}+\mathrm{Asn} / \mathrm{Asn}$ & $1.238(1.001-1.537)$ & 0.943 & $0.0 \%$ & 0.049 \\
\hline $\mathrm{Thr} / \mathrm{Thr}+\mathrm{Asn} / \mathrm{Ser}$ & $0.999(0.198-5.035)$ & 0.001 & $82.3 \%$ & $0.999^{R}$ \\
\hline $\mathrm{Ala} / \mathrm{Ala}+\mathrm{Ser} / \mathrm{Ser}$ & $0.583(0.316-1.074)$ & 0.076 & $56.4 \%$ & $0.083^{\mathrm{R}}$ \\
\hline $\mathrm{Ala} / \mathrm{Ala}+\mathrm{Asn} / \mathrm{Asn}$ & $0.784(0.262-2.352)$ & 0.827 & $0.0 \%$ & 0.665 \\
\hline $\mathrm{Ala} / \mathrm{Ala}+\mathrm{Asn} / \mathrm{Ser}$ & $2.521(0.444-14.320)$ & 0.018 & $70.2 \%$ & $0.297^{\mathrm{R}}$ \\
\hline Thr/Ala + Ser/Ser & $2.390(0.957-5.969)$ & 0.395 & $0.0 \%$ & 0.062 \\
\hline $\mathrm{Thr} / \mathrm{Ala}+\mathrm{Asn} / \mathrm{Asn}$ & $0.737(0.245-2.211)$ & 0.001 & $81.8 \%$ & $0.586^{\mathrm{R}}$ \\
\hline $\mathrm{Thr} / \mathrm{Ala}+\mathrm{Asn} / \mathrm{Ser}$ & $0.789(0.422-1.475)$ & 0.000 & $88.0 \%$ & $0.458^{\mathrm{R}}$ \\
\hline
\end{tabular}

$\mathrm{FSHR}=$ follicle stimulating hormone receptor; $\mathrm{OR}=$ odds ratio; $\mathrm{CI}=$ confidence interval; ${ }^{\mathrm{R}}$ random-effects model was used; otherwise, fixed-effects model was used; $\mathrm{P}_{\mathrm{H}}$ and $\mathrm{I}^{2}$ test for heterogeneity; $\mathrm{P}$ value from $\mathrm{Z}$ test.

\section{DISCUSSION}

Male infertility has become a major social problem that affects men's health and family happiness. In recent years, with the development of assisted reproductive technology (ART), the technologies of in vitro fertilization and intracytoplasmic sperm injection have been applied to help infertile couples to have children of their own, but these may also have negative effects. Although in recent years studies have found that, compared with natural pregnancy, ART does not carry increased risks of adverse health in the offspring, the finding that ART offspring have higher risks of birth defects, low birth weight, chromosomal abnormalities, and increased incidence of rare genetic disorders has motivated investigations of its safety issues in further depth (Hansen et al., 2005; Schieve et al., 2007; Davies et al., 2012). It has therefore become an important goal to illuminate the pathogenesis of infertility and explore the newly identified genes related to male infertility.

It is well known that the interaction between FSH and FSHR plays an indispensable role in normal gametes. In males, FSH regulates the function of Sertoli cells by its surface receptor (FSHR) (Laan et al., 2012). However, the influence and importance of FSHR variants on infertility risk is not completely understood. At present, the association between FSHR gene polymorphisms and the risk of male infertility has been reported both in China and 
abroad, the conclusions from these studies have been inconsistent. Some studies have reported no significant association between the FSHR gene Thr307Ala and Asn680Ser polymorphisms and male infertility, and found that these polymorphisms also had no effect on serum FSH level or semen quality (Ghirelli-Filho et al., 2012). However, Shimoda et al. (2009) and Safarinejad et al. (2011) reported that the combination genotypes Thr/Ala-Ser/Asn increased the risk of male infertility. Since then, another study in the Yangtze River delta region of China also reported a similar result (Song et al. 2013). Based on the above research, it was assumed that FSHR polymorphisms might indeed play a certain role in male infertility.

In this study, we explored the association between the FSHR Thr307Ala and Asn680Ser polymorphisms and male infertility risk in Shanxi Province of North China. Results from this study failed to demonstrate significant individual associations between the FSHR gene Thr307Ala and Asn680Ser polymorphisms and male infertility. When the combined genotypes of both Thr307Ala and Asn680Ser polymorphisms were analyzed, we found an association between the Thr/Ala + Asn/Asn combined genotypes and male infertility. Considering the relatively smaller sample size in this analysis, we combined all available studies in a meta-analysis. We also found no association between the individual FSHR Thr307Ala and Asn680Ser polymorphisms and the risk of male infertility. This was consistent with a previous meta-analysis (Wu et al., 2012). The association between the combined genotypes of FSHR polymorphisms and the risk of male infertility were also assessed by our meta-analysis, which found that the combined genotypes of $\mathrm{Thr} / \mathrm{Thr}+\mathrm{Asn} / \mathrm{Asn}$ increased the risk of male infertility.

It should be pointed out that there are also some limitations and insufficiencies from the meta-analysis in this study, such as inadequate sample size, inappropriate control subjects, positive publication bias, and ethnic and geographic differences. At the same time, the metaanalysis of the association between the combined genotypes of FSHR polymorphisms and the risk of male infertility included only four studies, which may have reduced the statistical power. Therefore, future research should focus on expanding the sample size and sample types, and access to a large sample base from different countries, races, regions, and medical centers.

In conclusion, our study and previously published related analyses indicates that there is no significant association between the FSHR gene Thr307Ala and Asn680Ser polymorphisms and the risk of male infertility. However, the combined genotypes of both Thr307Ala and Asn680Ser polymorphisms might have some effect on male infertility.

\section{ACKNOWLEDGMENTS}

Research supported by the International Science and Technology Cooperation Project in Shanxi Province (\#2011081070) and the Overseas Returnee Research Fund in Shanxi Province (2010). Furthermore, we are very grateful to Dr. Yi Luo (University of Iowa) for editing the manuscript.

\section{REFERENCES}

Ahda Y, Gromoll J, Wunsch A, Asatiani K, et al. (2005). Follicle-stimulating hormone receptor gene haplotype distribution in normozoospermic and azoospermic men. J. Androl. 26: 494-499.

Balkan M, Gedik A, Akkoc H, Izci Ay O, et al. (2010). FSHR single nucleotide polymorphism frequencies in proven fathers and infertile men in Southeast Turkey. J. Biomed. Biotechnol. 2010: 640318.

Davies MJ, Moore VM, Willson KJ, Van Essen P, et al. (2012). Reproductive technologies and the risk of birth defects. N. Engl. J. Med. 366: 1803-1813. 
Egger M, Davey Smith G, Schneider M and Minder C (1997). Bias in meta-analysis detected by a simple, graphical test. BMJ 315: 629-634.

Forti G and Krausz C (1998). Clinical review 100: Evaluation and treatment of the infertile couple. J. Clin. Endocrinol. Metab. 83: 4177-4188.

Ghirelli-Filho M, Peluso C, Christofolini DM, Gava MM, et al. (2012). Variants in follicle-stimulating hormone receptor gene in infertile Brazilian men and the correlation to FSH serum levels and sperm count. Reprod. Sci. 19: 733-739.

Grigorova M, Punab M, Poolamets O, Sober S, et al. (2013). Study in 1790 Baltic men: FSHR Asn680Ser polymorphism affects total testes volume. Andrology 1: 293-300.

Hansen M, Bower C, Milne E, de Klerk N, et al. (2005). Assisted reproductive technologies and the risk of birth defects - a systematic review. Hum. Reprod. 20: 328-338.

Higgins JP and Thompson SG (2002). Quantifying heterogeneity in a meta-analysis. Stat. Med. 21: 1539-1558.

Krausz C (2011). Male infertility: pathogenesis and clinical diagnosis. Best Pract. Res. Clin. Endocrinol. Metab. 25: 271285.

Laan M, Grigorova M and Huhtaniemi IT (2012). Pharmacogenetics of follicle-stimulating hormone action. Curr. Opin. Endocrinol. Diabetes Obes. 19: 220-227.

Lazaros L, Xita N, Kaponis A, Zikopoulos K, et al. (2008). Evidence for association of sex hormone-binding globulin and androgen receptor genes with semen quality. Andrologia 40: 186-191.

Lend AK, Belousova A, Haller-Kikkatalo K, Punab M, et al. (2010). Follicle-stimulating hormone receptor gene haplotypes and male infertility in estonian population and meta-analysis. Syst. Biol. Reprod. Med. 56: 84-90.

Li Y, Gu A, Yang H, Ding X, et al. (2011). FSH receptor gene polymorphisms in fertile and infertile Han-Chinese males. Clin. Chim. Acta 412: 1048-1052.

Luo H, Li H, Yao N, Hu L, et al. (2014). Association between 3801T $>$ C polymorphism of CYP1A1 and idiopathic male infertility risk: A systematic review and meta-analysis. PLoS One 9:e86649.

Munafo MR, Clark TG and Flint J (2004). Assessing publication bias in genetic association studies: evidence from a recent meta-analysis. Psychiatry Res. 129: 39-44.

Nieschlag E, Simoni M, Gromoll J and Weinbauer GF (1999). Role of FSH in the regulation of spermatogenesis: clinical aspects. Clin. Endocrinol.(Oxf.) 51: 139-146.

Pengo M, Ferlin A, Arredi B, Ganz F, et al. (2006). FSH receptor gene polymorphisms in fertile and infertile Italian men. Reprod. Biomed. Online 13: 795-800.

Plant TM and Marshall GR (2001). The functional significance of FSH in spermatogenesis and the control of its secretion in male primates. Endocr. Rev. 22: 764-786.

Safarinejad MR, Shafiei N and Safarinejad S (2011). Evaluating the role of the FSH receptor gene Thr307-Ala and Asn680-Ser polymorphisms in male infertility and their association with semen quality and reproductive hormones. BJU Int. 108: E117-125.

Schieve LA, Cohen B, Nannini A, Ferre C, et al. (2007). A population-based study of maternal and perinatal outcomes associated with assisted reproductive technology in Massachusetts. Matern. Child Health J. 11:517-525. doi:10.1007/ s10995-007-0202-7

Shimoda C, Koh E, Yamamoto K, Matsui F, et al. (2009). Single nucleotide polymorphism analysis of the folliclestimulating hormone (FSH) receptor in Japanese with male infertility: identification of codon combination with heterozygous variations of the two discrete FSH receptor genes. Endocr. J. 56: 859-865.

Simoni M, Gromoll J and Nieschlag E (1997). The follicle-stimulating hormone receptor: biochemistry, molecular biology, physiology, and pathophysiology. Endocr. Rev. 18: 739-773.

Song D, Zhang Z, Zhang H, Zhou W, et al. (2013). Relationship of single nucleotide polymorphism of follicle-stimulating hormone receptor gene and severe oligoasthenozoospermia in yangtze river delta of China. Reprod. Contracep. 33: 294-299

Themmen APN and Huhtaniemi IT (2000). Mutations of gonadotropins and gonadotropin receptors: elucidating the physiology and pathophysiology of pituitary-gonadal function. Endocr. Rev. 21: 551-583.

World Health Organization, Department of Reproductive Health and Research (2010).WHO Laboratory Manual for the Examination and Processing of Human Semen. 5th edn. Geneva: World Health Organization.

Wu W, Cai H, Sun H, Lu J, et al. (2012). Follicle stimulating hormone receptor G-29A, 919A >G, 2039A >G polymorphism and the risk of male infertility: a meta-analysis. Gene 505: 388-392.

Zalata AA, Hassan AH, Nada HA, Bragais FM, et al. (2008). Follicle-stimulating hormone receptor polymorphism and seminal anti-Müllerian hormone in fertile and infertile men. Andrologia 40: 392-397. 